\title{
Surgical economics: MACRA, MIPS, and bundles-Lessons learned in the first 3 years of a coronary artery bypass grafting alternative payment model
}

\author{
Daniel T. Engelman, MD
}

\author{
From the University of Massachusetts Medical School-Baystate, and Baystate Medical Center, Springfield, Mass \\ Received for publication July 22, 2016; revisions received Aug 12, 2016; accepted for publication Sept 13, 2016; \\ available ahead of print Oct 20, 2016. \\ Address for reprints: Daniel T. Engelman, MD, Associate Professor of Surgery, University of Massachusetts Med- \\ ical School-Baystate, 759 Chestnut St, Suite 4628, Springfield, MA 01199 (E-mail: Daniel.Engelman@ \\ baystatehealth.org). \\ J Thorac Cardiovasc Surg 2017;153:381-4 \\ $0022-5223 / \$ 36.00$ \\ Copyright () 2016 by The American Association for Thoracic Surgery \\ http://dx.doi.org/10.1016/j.jtcvs.2016.09.052
}

Feature Editor's Note-In this issue of the Journal, an article appears that ignites a view of the future. This future contains abbreviations and phrases that are foreign to most cardiothoracic surgeons. Abbreviations such as MACRA, PPACA, MIPS, ACO, BPCI, and the like send chills up and down the spine of most surgeons-but not Dan Engelman. Dr Engelman embraces these terms, and by doing so he paints a picture of the future that many surgeons find moderately painful.

Why should we listen to what Dan Engelman has to say? The answer is not as obvious as one might think. Underlying the list of abbreviations that define the new surgical economics is a concept that all cardiothoracic surgeons can embrace-quality. Coordination of care and rewards for good outcomes are the basis of the new surgical economic system. A big part of this new surgical economic system involves surgeons' accepting significant risk for patient outcomes. This is no different than what we already do on a daily basis. Surgeons agonize over every patient, every day. What is different is that surgeons are now part of a coordinated team that delivers timely and efficient care. Many surgeons, myself included, grew up in an era where surgeons, especially cardiothoracic surgeons, accepted responsibility for all of the things that happened to their patients. As a result, they believed that they could provide all the care for their patients better than anyone else. Much of this care, however, was not directly under the control of the surgeon. Some of this care could be done more efficiently by others. Some could be done with less expense. Some could be done better by including specialized support structures. These facts may be painful to accept, but sometimes the truth hurts, and it is not as though we have a choice.

There is a second message in Dan Engelman's article that is even more important than understanding the quality metrics underlying the abbreviations of the new surgical economics. The concept of risk adjustment is something that every surgeon understands at a visceral level. Patient risk

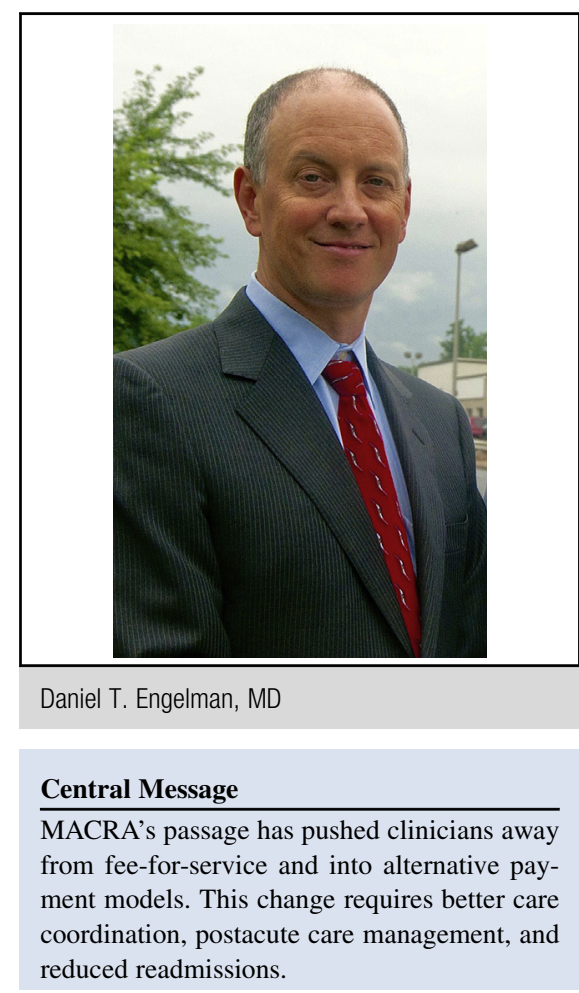

See Editorial Commentary page 385.

factors and operative complexity are variables that prevent patients from being grouped into simple, discrete financial categories. Dr Engelman points out that surgeons have to get engaged to make sure that bundled payments reflect our patients' case severities. Every patient presents a unique risk profile with unique requirements for care coordination and with unique cost structures. Surgeons need to speak up to bring home this point.

This article is must reading for cardiothoracic surgeons. It is a primer on the new surgical economics. It is clear that this new surgical economics is evolving and that the final version has not yet been written. Surgeons need to be part of this evolution, and a good starting point is Dr Engelman's article.

Victor A. Ferraris, $M D, P h D$

Busy cardiothoracic surgeons have not paid much attention to national health care policy legislature. Ensuring good 
outcomes and maximizing a caseload has provided occupational satisfaction and financial security. With little fanfare, however, and with huge potential repercussions, our physician Medicare payment reimbursement system has just radically changed. These changes may also rapidly extend to the commercial payers, and they will affect every practicing physician, both hospital employed and in private practice.

What has driven these changes? Between 1974 and 2009, health care costs skyrocketed as a share of the US gross domestic product, from $7 \%$ to $17 \%$. During the next 15 years, a declining US taxpaying workforce relative to a surging Medicare population is forecast to bankrupt Medicare. In the US, we spend $18 \%$ of our gross domestic product on health care, versus $9 \%$ to $11 \%$ for much of Europe. ${ }^{1}$ This averages to more than $\$ 8000$ US per person. Health insurance premiums have increased by $160 \%$ since 1999 , while workers' earnings have increased by only $50 \%{ }^{2}{ }^{2}$ Hospital care and physician services account for the largest shares of personal health care spending (38\% and $23 \%$, respectively, in 2014).

Coronary artery bypass grafting surgery total hospital and physician costs in 2013 were $\$ 75,000$ per patient in the US, versus $\$ 15,000$ to $\$ 40,000$ in Western Europe. ${ }^{4}$ Despite this large spending per capita, the United States has a life expectancy that is below that of many other developed nations. ${ }^{5}$ This rise in health care spending is unsustainable. As a result, in 2010 the US Congress passed the Patient Protection and Affordable Care Act (PPACA).

The PPACA mandated that all individuals have health coverage. This mandate immediately resulted in a sharp decrease in the proportion of uninsured persons, from $18 \%$ in 2009 to $9 \%$ in $2015 .^{6}$ The PPACA also included some adjustments to the Medicare Physician Payment System. And in 2015, Congress finally repealed the legislation that mandated Medicare physician payments reductions of almost $30 \%$ (the sustainable growth rate formula). In its place, Congress passed the Medicare Access and CHIP Reauthorization Act (MACRA). Although this replacement initially appeared to be quite favorable for physicians, MACRA imposed a number of important changes in the way Medicare will pay for services in the future. Most importantly, it attempted to better align quality and a reduction in unnecessary costs with physician payment.

MACRA will add strong financial incentives for physicians to become more financially accountable for quality and expenditure performance. By design, the new payment model will encourage physicians to join delivery systems that focus on non-fee-for-service alternative payment models (APMs). For those who chose to stay within the traditional delivery system, MACRA established a Meritbased Incentive Payment System (MIPS). The Center for
Medicare and Medicaid Services (CMS) would begin measuring performance in January 2017, with payments based on those measures beginning in 2019. In fact, most physicians will be in the MIPS program. Payment rates will be adjusted plus or minus $4 \%$ per year, increasing to $9 \%$ by 2022 , on the basis of performance measures. This is a budget neutral program, which implies that equal dollar amounts will go to physicians who attain performance measures above and below the average score. As such, it will require participants to achieve continuous improvements in an ever-increasing competitive environment. In addition, Medicare fees will increase by only $2.0 \%$ through 2022 and then will remain flat. As an alternative to this payment structure, those physicians who participate in an eligible Advanced APM, in which physicians bear significant downside risk, will receive a 5\% payment bonus and will also be exempt from the administrative requirements and uncertainties of MIPS. In addition, they can also participate in any additional payments that result from being part of an approved APM system.

At this time, CMS has identified only 6 APMs that qualify as Advanced APMs for MIPS exclusion. These include Comprehensive End-Stage Renal Disease Care, the Oncology Care Model, and the Next Generation Accountable Care Organization (ACO) Model. CMS estimates that as many as $90 \%$ of eligible clinicians will be in the MIPS program in 2017 and as few as $10 \%$ will be in an Advanced APM. ${ }^{7}$ It is anticipated that CMS will soon broaden its definition of qualifying Advanced APMs. ${ }^{8}$

Beginning in 2013, our hospital entered into the Bundled Payments for Care Improvement Initiative (BPCI) for all isolated coronary artery bypass grafting procedures covered by Medicare. Bundled payment is intended to decrease spending through several mechanisms: (1) a reduction in the number of unnecessary physician services during a hospitalization, (2) more judicious use of health care resources during the hospital stay, and (3) a reduction in postdischarge costs, including unnecessary postacute care services and avoidable readmissions. If the costs of an episode of care are less than the bundled payment amount, the providers (hospital and physicians) can keep the difference; if the costs of care exceed the bundled payment amount, however, the providers bear financial liability. In our BPCI APM, the episode of care includes a Medicare beneficiary's inpatient stay in the acute care hospital, postacute care, and all related services during the episode of care, which ends 90 days after hospital discharge. In addition, participating hospitals agree to a $2 \%$ upfront fee reduction.

Functioning in a bundle APM requires the administrative, financial, and infrastructure support best suited to a large institution. Hospitals must provide appropriate data, resources, and incentives. Our hospital has created a 
replicable model to implement bundled payment programs by emphasizing collaboration among our clinical divisions and those of health care quality and finance. We also have a physician health organization that is well versed in risk arrangements to support our endeavors. Nonetheless, early on we learned some valuable lessons to ensure success in a bundled payment APM:

1. To ensure that the Medicare payment amounts are fair, some adjustment for patient severity must be included in the calculations. If bundled payments do not take severity of disease into account, providers may not want to care for sicker patients because of the risk of financial loss. More than ever, providers must ensure accurate and complete documentation to maximize charge capture and correctly document level of acuity. Accurate coding, which incorporates key documentation, will positively affect both reimbursement and expected morbidity and mortality.

2. Coordination of care is essential. A dedicated care coordinator needs to follow this cohort of patients, beginning with preoperative education about length of stay expectations and especially touching on the need for family support at home on discharge. During the hospitalization, the coordinator needs to identify hospital barriers to a timely discharge. We were able to decrease our length of stay and facilitate the discharge of patients with subtherapeutic international normalized ratios and close daily home blood work. After patients' discharge home, close follow-up by phone, with daily weights, medication reconciliation, and early office postoperative appointments, prevented emergency department visits. All readmissions were closely scrutinized for potentially avoidable events.

3. During the index admission, physicians can reduce unnecessary medical expenses if they are properly engaged. A recent study in JAMA found that peer comparison resulted in a $16 \%$ drop in unnecessary prescriptions. ${ }^{9}$ We found that by sharing utilization metrics among the cardiac surgeons, we could successfully drive down hospital costs, because physicians hate being outliers. Medicare has already begun publishing comparative data as they emphasize the patient experience. The Hospital Consumer Assessment of Healthcare Providers and Systems (HCAHPS) survey is the first national, standardized, publicly reported survey of patients' perspectives of hospital care. By making quality and satisfaction reports publicly available, Medicare has created an incentive for physicians and hospitals to pay attention to the patient experience.

4. To succeed in a bundled payment arrangement, one must reduce readmissions. After coronary artery bypass grafting surgery, readmission rates are between $13 \%$ and $24 \%$. Readmission predictor models have been developed. ${ }^{10}$ On discharge, we identify those patients at high risk for read- mission. Our clinical coordinator then follows a patient at risk by phone, schedules early postoperative visits, enrolls the patient in a heart failure rehabilitation clinic, and coordinates care with the patient's primary care physician. In addition, all postoperative patients entering our emergency department trigger an electronic notification to our inpatient service before their admission for expedited review and disposition.

5. The postacute disposition was the single greatest variable affecting a positive margin in our bundle. By altering the patient and family expectations, earlier frequent daily mobilization, and possibly extending inpatient stays for an extra day, we were able to increase the percentage of patients discharged to home with visiting nurse services versus discharging to a skilled nursing facility. For those patients who were sent to a skilled nursing facility, close coordination with the facility decreased the postacute length of stay, thereby reducing overall costs to the bundle and improving patient satisfaction. We have also developed a preferred provider skilled nursing facility network to align more closely with best practice standards, track outcomes, and improve communication between the primary cardiac surgical in-patient team and our postacute care partners.

In the future, cardiothoracic surgeons will probably benefit from joining an APM, such as a bundled payment initiative. At this time, however, to qualify for MIPS exclusion, the only clear advanced APM option is to join a consolidated risk-bearing ACO with significant "downside risk." Most recently, on July 25, 2016, CMS proposed a new mandatory bundled payment system for bypass surgery billed through Medicare that would launch in July 2017. The participants would be 98 randomly chosen cities among 294 eligible metropolitan areas. In addition, CMS stated that these bundled payment models might qualify for the Advanced APM track of MACRA. ${ }^{11}$

It is clear that the federal government has created a payment system that encourages changing physician payment from fee for service to payment that is based on performance metrics, patient experience, and patient outcomes. There is an early opportunity for significant financial reward from a high-value program that is focused on quality metrics, HCAHPS scores, care coordination, and the postacute disposition. Similar to how cardiac surgeons have led the medical community in reporting outcomes by using the Society of Thoracic Surgeons database, the next hurdle will be maximizing reimbursement through an optimized, patientfocused APM.

\section{ADDENDUM}

On December 20, 2016, CMS created new 90-day posthospitalization bundled payment programs for acute myocardial infarction and coronary artery bypass graft 
patients. The cardiac bundle programs will be mandatory in 98 geographic areas. ${ }^{12}$ Beginning in 2018, these bundles will qualify as APMs under MACRA, thereby providing exclusion from MIPS.

\section{Conflict of Interest Statement}

Author has nothing to disclose with regard to commercial support.

The author is grateful to Dr Stuart Altman, Professor of National Health Policy at Brandeis University, and the bundled care team at Baystate Medical Center for their assistance with this editorial.

\section{References}

1. Organisation for Economic Co-operation and Development. OECD health statistics 2016. Available at: http://www.oecd.org/els/health-systems/health-data.htm. Accessed October 12, 2016

2. Kaiser Family Foundation. The Henry J. Kaiser Family Foundation. Available at: http://kff.org. Accessed August 12, 2016.

3. Medicare Payment Advisory Commission. Report to the Congress: Medicare payment policy. Washington, DC: Medicare Payment Advisory Commission; 2016:7-10.

4. International Federation of Health Plans. 2013 comparative price report: variation in medical and hospital prices by country. Available at: https://static1. squarespace.com/static/518a3cfee4b0a77d03a62c98/t/534fc9ebe4b05a88e5fbab70/ 1397737963288/2013+iFHP+FINAL+4+14+14.pdf. Accessed August 12, 2016.

5. Peterson-Kaiser Health System Tracker. How does U.S. life expectancy compare to other countries? Available at: http://www.healthsystemtracker.org/chart-collection/ how-does-u-s-life-expectancy-compare-to-other-countries/. Accessed October 12, 2016.

6. Centers for Disease Control and Prevention. NHIS data, questionnaires and related documentation. Available at: http://www.cdc.gov/nchs/nhis/dataquestionnaires-documentation.htm. Accessed August 12, 2016.

7. Mechanic RE. When new Medicare payment systems collide. $N$ Engl J Med. 2016;374:1706-9.

8. Clough JD, McClellan M. Implementing MACRA: implications for physicians and for physician leadership. JAMA. 2016;315:2397-8.

9. Meker D, Linder JA, Fox CR, Friedberg MW, Persell SD, Goldstein NJ, et al. Effect of behavioral interventions on inappropriate antibiotic prescribing among primary care practices: a randomized clinical trial. JAMA. 2016; 315:562-70.

10. Shahian DM, He X, O'Brien SM, Grover FL, Jacobs JP, Edwards FH, et al. Development of a clinical registry-based 30-day readmission measure for coronary artery bypass grafting surgery. Circulation. 2014;130: 399-409.

11. Centers for Medicare \& Medicaid Services. Notice of proposed rulemaking for bundled payment models for high-quality, coordinated cardiac and hip fracture care. Available at: https://www.cms.gov/Newsroom/MediaReleaseDatabase/ Fact-sheets/2016-Fact-sheets-items/2016-07-25.html. Accessed August 12, 2016.

12. Centers for Medicare \& Medicaid Services. Episode payment models: general information. Available at: https://innovation.cms.gov/initiatives/epm. Accessed December 22, 2016. 